\title{
Pregnancy Outcomes in Pregnant Women with Subchorionic Hematoma
}

\author{
Irina O. Bushtyreva ${ }^{1,2}, \mathrm{PhD}, \mathrm{ScD}$; Natalia B. Kuznetsova ${ }^{1,2}, \mathrm{PhD}$; \\ Victoria V. Barinova ${ }^{1,2 *}$, PhD; Anna V. Kovaleva ${ }^{2}$; Maria P. Dmitrieva ${ }^{2}$ \\ ${ }^{I}$ Rostov State Medical University, Rostov-on-Don, Russia \\ ${ }^{2}$ Rostov State Perinatal Centre, Rostov-on-Don, Russia
}

\begin{abstract}
Background: The role of subchorionic hematoma ( $\mathrm{SCH})$ in the first trimester of pregnancy remains open for discussion. Some authors claim that SCH does not affect the pregnancy; others have found that it is a serious risk factor for adverse pregnancy outcome. The objective of the present study was to explore the outcomes of pregnancy in patients with SCH diagnosed in the first trimester.

Methods and Results: The study involved 194 pregnant women who were in terms of 6 to 12 weeks: 115 women with SCH (Group 1) and 79 apparently healthy pregnant women (Group 2). A missed miscarriage was observed in 27/23\% women of Group 1 and in $4 / 5 \%$ of Group $2(P<0.001)$, recurrent threat of miscarriage in $27 / 23 \%$ and in $4 / 5 \%(P<0.001)$, recurrent bleeding in $14 / 12 \%$ and $2 / 3 \%(P<0.02)$, and the short cervix syndrome in $22 / 19 \%$ and $5 / 6 \%(P<0.03)$ women, respectively.

Conclusion: The results of our study show that the presence of SCH adversely affects the first half of pregnancy, leading to recurrent threatened abortion, recurrent threat of miscarriage, missed miscarriage until 12 weeks of gestation, and the short cervix syndrome. (Int I Biomed. 2015;5(3):137-140.)
\end{abstract}

Keywords: subchorionic hematoma; miscarriage; short cervix syndrome.

\section{Introduction}

Vaginal bleeding during the first half of pregnancy occurs in approximately $25 \%$ of women and is associated with early pregnancy loss $[1,2]$. Subchorionic hematoma $(\mathrm{SCH})$, intrauterine hematoma, or retrochorial hematoma are common ultrasonographic findings that may be associated with first-trimester bleeding [3]. According to the literature, the incidence of $\mathrm{SCH}$ in the first trimester in a general obstetric population is $3.1 \%$ [4], the frequency of $\mathrm{SCH}$ in the group with threatened spontaneous miscarriages is $5.2 \%$ [1], and the frequency of $\mathrm{SCH}$ is significantly higher in the in vitro fertilization group (22.4\%) [5]. Additionally, pregnant women with $\mathrm{SCH}$ in the first trimester show changes in vaginal flora in the second trimester, which suggests a possible association with subchorionic hematoma and vaginal flora change [6].

Ultrasonographically detected $\mathrm{SCH}$ increases the

*Corresponding author: Victoria V. Barinova, PhD. Rostov State Medical University, Rostov-on-Don, Russia. E-mail: Victoriabarinova@yandex.ru risk of miscarriage in patients with vaginal bleeding and of threatened abortion during the first 20 weeks of gestation [7]. A very large first-trimester hematoma is associated with a $46 \%$ risk of adverse pregnancy outcome (spontaneous abortion and premature rupture of membranes) [3]. In the case of prolongation of pregnancy, patients with $\mathrm{SCH}$ have a higher risk of maternal and neonatal complications of hypertension in pregnancy, preeclampsia, placental abruption, fetal growth retardation, fetal distress, and others [4,8-10], but still there is no consensus regarding the nature of these complications. Thus, conflicting versions around $\mathrm{SCH}$ and its role in the gestational process leave the questions open for discussion.

The objective of the present study was to explore the outcomes of pregnancy in patients with SCH diagnosed in the first trimester.

\section{Materials and Methods}

The study was conducted in Rostov-on-Don State Perinatal Center for the period from January 1, 2013, to January 1, 2015. The study was conducted in accordance 
with ethical principles of the Declaration of Helsinki. It was approved by Rostov-on-Don State Perinatal Center Ethics Committee. Written informed consent was obtained from all participants.

The criteria for inclusion in the study were the presence of SCH diagnosed by ultrasound during 6-12 weeks of pregnancy and the presence of a viable embryo in the primary ultrasound examination. Exclusion criteria were pregnancy after assisted reproductive technologies, multiple pregnancies, and cases of detected congenital anomalies.

Ultrasound examination was performed on the PhilipsHD 11, and evaluated the coccyx-rump length, heart rate, yolk sac and its average internal diameter, localization of chorion and its structure, structural features of the uterus wall and ovary. The size, the volume of $\mathrm{SCH}$, and its location and stage of development were evaluated.

A heart rate of the embryo less than 110 beats per minute was assessed as bradycardia and more than 180 beats per minute as tachycardia.

The following topographies of hematomas were determined: the bottom of the uterus, the back wall, the front wall of the uterus, the area that covers the internal os of the cervix. Localization of SCH was classified as corporal (located along the wall of the uterus, in the bottom) and supracervical (above the internal os of cervix). The size of the hematoma was determined by measuring the transverse, anteriorposterior, longitudinal dimensions with automatic calculation of volume. We classified the stages of SCH development as (1) organized, (2) with signs of organization, and (3) unorganized.

Moreover, we analyzed the following complications of pregnancy: missed miscarriage, hypertension during pregnancy, and preeclampsia; and the following complications of delivery: hypotonic bleeding, rate of placenta previa and placenta increta, premature detachment of placenta, pathology of placenta discharge, preterm delivery, premature rupture of membranes, and fetal growth retardation.

Statistical analysis was performed using StatSoft Statistica v6.0. Group comparisons with respect to categorical variables are performed using chi-square tests or, alternatively, Fisher's exact test when expected cell counts were less than 5 . The probability of an adverse outcome of pregnancy was determined using logistic regression (with calculation of odds ratios (OR), relative risk (RR), and confidence intervals (CI)). A probability value of $P<0.05$ was considered statistically significant.

\section{Results}

The study included 194 pregnant women at 6 to 12 weeks of pregnancy. The study group included 115 women with SCH (Group 1); the control group (Group 2) included 79 apparently healthy pregnant women without $\mathrm{SCH}$. The average age was $29.7 \pm 4.3$ years in Group 1 and $29.4 \pm 5.4$ years in Group 2; the groups were matched by age. The somatic status of patients in Groups 1 and 2 was identical: chronic pyelonephritis, chronic gastritis, chronic pancreatitis, and hypertension were marked in an equal percentage of cases.

Corporal localization of the hematoma was more common than supracervical $-82 / 71 \%$ and $33 / 29 \%$, respectively. SCH volume in patients of Group 1 was 0.027 to $3.68 \mathrm{~cm}^{3}$, median $(\mathrm{Me})-0.605 \mathrm{~cm}^{3}$, interquartile range $(25$ th and 75 th percentiles) from 0.225 to $1.254 \mathrm{~cm}^{3}$. Time of $\mathrm{SCH}$ formation was evaluated by echographic signs of hematoma organization: unorganized hematomas were observed in $44 / 38 \%$ of the women, signs of hematoma organization in $24 / 21 \%$, and organized hematoma in $47 / 41 \%$.

The results of our study show that the presence of SCH adversely affects the first half of pregnancy. The incidence of adverse pregnancy outcome in the first trimester in pregnant women of Group 1 was significantly higher compared with Group 2. Missed miscarriage was observed in $27 / 23 \%$ women of Group 1 and in $4 / 5 \%$ of Group $2(P<0.05)$. In addition, a higher frequency of recurrent threat of miscarriage, recurrent bleeding, and the short cervix syndrome were observed in women of Group 1. At the same time, the presence of $\mathrm{SCH}$ increased the chance of the first half of pregnancy complications (recurrent threatened abortion, short cervix syndrome, recurrent vaginal bleeding in pregnancy) and adverse pregnancy outcomes in the first trimester (Table 1). The risk of pregnancy loss during the terms of 6 to 12 weeks in Group 1 patients was 4.64 times higher than those in Group $2(P=0.0005)$. Missed miscarriage during terms of 13 to 22 weeks was observed in $3 / 2.6 \%$ patients of Group 1 and was not observed in Group 2.

Table 1.

Complications of the first half of pregnancy in patients with SCH and in the control group

\begin{tabular}{|l|c|c|c|c|c|c|}
\hline $\begin{array}{c}\text { Complications of } \\
\text { the first half of } \\
\text { pregnancy }\end{array}$ & $\begin{array}{c}\text { Group 1 } \\
(\mathrm{n}=115)\end{array}$ & $\begin{array}{c}\text { Group 2 } \\
(\mathrm{n}=79)\end{array}$ & $\begin{array}{c}\text { Yates' } \\
\text { chi-square } \\
P \text {-value }\end{array}$ & $\begin{array}{c}\mathrm{RR}, 95 \% \mathrm{CI} \text {, and } \\
P \text {-value }\end{array}$ & $\begin{array}{c}\text { OR, 95\% CI, and } \\
P \text {-value }\end{array}$ & $\begin{array}{c}\text { Logistic } \\
\text { regression } \\
P \text {-value }\end{array}$ \\
\hline $\begin{array}{l}\text { Missed miscarriage } \\
(6-12 \text { weeks) }\end{array}$ & $27(23 \%)$ & $4(5 \%)$ & $\begin{array}{c}10.496 \\
P<0.0012\end{array}$ & $\begin{array}{c}4.64(1.69-12.73) \\
P=0.0029\end{array}$ & $\begin{array}{c}5.75(1.93-17.18) \\
P=0.0017\end{array}$ & 0.0005 \\
\hline $\begin{array}{l}\text { Missed miscarriage } \\
(13-22 \text { weeks) }\end{array}$ & $3(3 \%)$ & $0(0 \%)$ & - & - & - & - \\
\hline $\begin{array}{l}\text { Recurrent threatened } \\
\text { abortion }\end{array}$ & $27(23 \%)$ & $4(5 \%)$ & $\begin{array}{c}10.496 \\
P<0.0012\end{array}$ & $\begin{array}{c}4.64(1.69-12.73) \\
P=0.0029\end{array}$ & $\begin{array}{c}5.75(1.93-17.18) \\
P=0.0017\end{array}$ & 0.0005 \\
\hline $\begin{array}{l}\text { Short cervix } \\
\text { syndrome }\end{array}$ & $22(19 \%)$ & $5(6 \%)$ & $\begin{array}{c}5.382 \\
P<0.0203\end{array}$ & $\begin{array}{c}3.02(1.20-7.64) \\
P=0.0195\end{array}$ & $\begin{array}{c}3.5(1.26-9.69) \\
P=0.0158\end{array}$ & 0.0115 \\
\hline $\begin{array}{l}\text { Recurrent vaginal } \\
\text { bleeding }\end{array}$ & $14(12 \%)$ & $2(3 \%)$ & $\begin{array}{c}4.55 \\
P<0.0329\end{array}$ & $\begin{array}{c}4.81(1.12-20.58 \\
P=0.0342\end{array}$ & $\begin{array}{c}5.34(1.18-24.18) \\
P=0.0298\end{array}$ & 0.0168 \\
\hline
\end{tabular}


Table 2.

Complications of the second half of pregnancy and delivery in patients with SCH and in the control group

\begin{tabular}{|c|c|c|c|c|c|c|}
\hline $\begin{array}{l}\text { Complications of } \\
\text { the third trimester }\end{array}$ & $\begin{array}{l}\text { Group 1a } \\
(\mathrm{n}=85)\end{array}$ & $\begin{array}{l}\text { Group } 2 \mathrm{a} \\
(\mathrm{n}=63)\end{array}$ & $\begin{array}{c}\text { Fisher's exact } \\
\text { test (2-Tail) } \\
P \text {-value }\end{array}$ & $\begin{array}{c}\mathrm{RR}, 95 \% \mathrm{CI} \text {, and } \\
\text { P-value }\end{array}$ & $\begin{array}{c}\text { OR, } 95 \% \mathrm{CI} \text {, and } \\
P \text {-value }\end{array}$ & $\begin{array}{l}\text { Logistic } \\
\text { regression } \\
P \text {-value }\end{array}$ \\
\hline $\begin{array}{l}\text { Hypertension } \\
\text { associated with } \\
\text { pregnancy }\end{array}$ & $1(1.2 \%)$ & $1(1.6 \%)$ & 1.0 & $\begin{array}{c}0.74(0.05-11.62) \\
P=0.8311\end{array}$ & $\begin{array}{c}0.74(0.04-12.03) \\
P=0.8311\end{array}$ & $>0.05$ \\
\hline Preeclamsia & $3(3.5 \%)$ & $1(1.6 \%)$ & 0.6367 & $\begin{array}{c}2.22(0.24-20.88) \\
P=0.4844\end{array}$ & $\begin{array}{c}2.27(0.23-22.34) \\
P=0.4838\end{array}$ & $>0.05$ \\
\hline Hypotonic bleeding & $1(1,2 \%)$ & $0(0 \%)$ & 1.0 & - & - & - \\
\hline Placenta previa & $3(3.5 \%)$ & $1(1.6 \%)$ & 0.6367 & $\begin{array}{c}2.22(0.24-20.88) \\
P=0.4844\end{array}$ & $\begin{array}{c}2.27(0.23-22.34) \\
P=0.4838\end{array}$ & $>0.05$ \\
\hline Placenta increta & $1(1.2 \%)$ & $0(0 \%)$ & 1.0 & - & - & - \\
\hline Placental abruption & $2(2.3 \%)$ & $0(0 \%)$ & 0.5077 & - & - & - \\
\hline $\begin{array}{l}\text { Retained portions } \\
\text { of placenta }\end{array}$ & $0(0 \%)$ & $2(3.2 \%)$ & 0.1795 & - & - & - \\
\hline Preterm birth & $8(9.4 \%)$ & $1(1.6 \%)$ & 0.07878 & $\begin{array}{c}5,93(0.76-46.21) \\
P=0.0893\end{array}$ & $\begin{array}{c}6.44(0.78-52.90) \\
P=0.0829\end{array}$ & $>0.05$ \\
\hline $\begin{array}{l}\text { Preterm rupture of } \\
\text { membranes }\end{array}$ & $2(2.3 \%)$ & $0(0 \%)$ & 0.5077 & - & - & - \\
\hline $\begin{array}{l}\text { Intrauterine growth } \\
\text { retardation }\end{array}$ & $8(9.4 \%)$ & $9(14.3 \%)$ & 0.4371 & $\begin{array}{c}0.66(0.27-1.61) \\
P=0.3607\end{array}$ & $\begin{array}{c}0.62(0.23-1.72) \\
P=0.3609\end{array}$ & $>0.05$ \\
\hline
\end{tabular}

Women with prolonged pregnancy $(85 / 74 \%)$ were subjected to further clinical monitoring (Group 1a), including the analysis of long-term complications of pregnancy and its outcomes. The control group of patients with prolonged pregnancy (Group 2a) included 63 apparently healthy women out of 79 women participating in the evaluation in the first trimester, 12 of which ended in surgical abortions on request up to 12 weeks, and 4 of which ended in missed miscarriage up to 12 weeks.

Statistical processing using logistic regression showed how many times the chances of complications increase during the second half of pregnancy in the presence of SCH in the first trimester (Table 2). Analysis of perinatal outcomes in patients with $\mathrm{SCH}$ in our study showed that in this group of pregnant women the risk of preterm birth, preeclampsia, hypertension associated with pregnancy, premature rupture of membranes, placenta previa, placenta increta, placental abruption, retained portions of placenta, and fetal growth retardation is not different from pregnant women without $\mathrm{SCH}$.

However, the rate of preterm birth in Group 1a was significantly higher than in Group 2a: 9.4\% vs. 1.6\% $(P<0.05)$; that definitely needs a further study, with the expansion of sample size and analysis of received data.

\section{Discussion}

The results of our study show that the presence of $\mathrm{SCH}$ adversely affects the first half of the pregnancy. The incidence of pathological placentation, recurrent threatened abortion, recurrent threat of miscarriage, and missed miscarriage was higher in pregnant women with $\mathrm{SCH}$. Our results relating the correlation between $\mathrm{SCH}$ and missed miscarriage are consistent with those published in other studies $[4,9]$. S. Nagy et al. [4] found that $18.7 \%$ of women had subsequent pregnancy loss in terms less than 24 weeks.

M. Tuuli et al. [9] found that patients with SCH had 2.18 higher risk of spontaneous abortion. In addition, the results of our study show that patients with SCH have higher frequency of short cervix syndrome.

In a univariable analysis [10], the presence of a $\mathrm{SCH}$ was significantly associated with a shorter mean cervical length as well as a cervical length less than the 10th percentile $(4.27 \mathrm{~cm}$ vs $4.36 \mathrm{~cm}, P=0.038 ; 1.9 \%$ vs $0.5 \%, P=0.006$, respectively); preterm birth also was more common in women with an $\mathrm{SCH}$ $(12.5 \%$ vs $7.3 \%$ in women without a first-trimester $\mathrm{SCH}$, $P=0.001$ ). The fact that first-trimester $\mathrm{SCH}$ is associated with both a shorter cervical length and preterm birth suggests the possibility that mechanisms other than cervical shortening may be involved in preterm birth pathogenesis.

We did not find a correlation between the presence of SCH diagnosed at 6 to 12 weeks and late pregnancy complications: preeclampsia, hypertension associated with pregnancy, preterm labor, premature rupture of membranes, placenta previa, placenta increta, placental abruption, retained portions of placenta, and fetal growth retardation.

In the discussion of the results, it should be said that even among those who find a correlation between $\mathrm{SCH}$ and late complications of pregnancy, there is no unanimity of opinion on the nature of these complications. Thus, S. Nagy et al. [4] found that patients with SCH had higher risk of preeclampsia, placental abruption, preterm delivery, fetal growth retardation, and higher frequency of children born 
with less weight than in women of the control group [4]. S. Norman et al. [8] published the results of a retrospective study and partly confirmed the results of S. Nagy et al. [4], showing a link between subchorionic hematoma and placental abruption, subchorionic hematoma and preterm delivery, but did not find a correlation between $\mathrm{SCH}$ and other complications of the gestational process: premature rupture of membranes, fetal growth retardation, fetal death and preeclampsia. Later, in 2011, M. G. Tuuli et al. [9] published a meta-analysis of studies of perinatal outcomes in patients with $\mathrm{SCH}$ which showed that patients with $\mathrm{SCH}$ had a 2.18 higher risk of spontaneous abortion, 2.9 higher risk of stillbirth, 5.7 higher risk of placental abruption, 1.4 higher risk of premature births and 1.64 higher risk of premature rupture of membranes. This analysis did not find a correlation between $\mathrm{SCH}$ and preeclampsia, hypertension associated with pregnancy, and low birth weight.

We should especially mention the frequency of preterm birth in pregnant women with SCH. In our study, we found a high incidence of preterm birth in women with $\mathrm{SCH}$; however, we did not find significant differences between patients with and without $\mathrm{SCH}$. In several large studies such an association was found [4,8-10]; however, those studies included large samples of pregnant women, and some have used other inclusion criteria. For example, S. M. Norman et al. [8], showed that women with ultrasound-detected $\mathrm{SCH}$ before 22 weeks of gestation are at increased risk of preterm delivery.

A large number of studies on the clinical value of $\mathrm{SCH}$ in the genesis of pregnancy complications underline the relevance of the considered clinical problem, and the role of $\mathrm{SCH}$ in the genesis of obstetric complications. Contradictions in the published results may be partly due to both objective and subjective reasons, such as ethnographic characteristics of the population, different inclusion criteria, and different terms of pregnancy of patients included in the study.

In summary, the results of our study show that the presence of SCH adversely affects the first half of pregnancy, leading to recurrent threatened abortion, recurrent threat of miscarriage, missed miscarriage until 12 weeks of gestation, and the short cervix syndrome.

\section{Competing interests}

The authors declare that they have no competing interests.

\section{References}

1. Soldo V, Cutura N, Zamurovic M. Threatened miscarriage in the first trimester and retrochorial hematomas: sonographic evaluation and significance. Clin Exp Obstet Gynecol. 2013;40(4):548-50.

2. Ben-Haroush A, Yogev Y, Mashiach R, Meizner I. Pregnancy outcome of threatened abortion with subchorionic hematoma: possible benefit of bed-rest? Isr Med Assoc J. 2003;5(6):422-4.

3. Leite J1, Ross P, Rossi AC, Jeanty P. Prognosis of very large first-trimester hematomas. J Ultrasound Med. 2006;25(11):1441-5.

4. Nagy S, Bush M, Stone J, Lapinski R, Gardó S. Clinical significance of subchorionic and retroplacental hematomas detected in the first trimester of pregnancy. Orv Hetil. 2005;146(42):2157-61. [Article in Hungarian]

5. Asato K, Mekaru K, Heshiki C, Sugiyama H, Kinjyo T, Masamoto H, et al. Subchorionic hematoma occurs more frequently in in vitro fertilization pregnancy. Eur J Obstet Gynecol Reprod Biol. 2014;181:41-4.

6. Yamada T, Atsuki Y, Wakasaya A, Kobayashi M, Hirano Y, Ohwada M.J. Characteristics of patients with subchorionic hematomas in the second trimester. Obstet Gynaecol Res. 2012; 38(1):180-4.

7. Şükür YE, Göç G, Köse O, Açmaz G, Özmen B, Atabekoğlu CS, et al. The effects of subchorionic hematoma on pregnancy outcome in patients with threatened abortion. $\mathrm{J}$ Turk Ger Gynecol Assoc. 2014;15(4):239-42.

8. Norman SM, Odibo AO, Macones GA, Dicke JM, Crane JP, Cahill AG. Ultrasound-detected subchorionic hemorrhage and the obstetric implications. Obstet Gynecol. 2010;116(2 Pt 1):311-5.

9. Tuuli MG, Norman SM, Odibo AO, Macones GA, Cahill AG. Perinatal outcomes in women with subchorionic hematoma: a systematic review and meta-analysis. Obstet Gynecol. 2011; 117(5):1205-12.

10. Palatnik A, Grobman WA. The relationship between firsttrimester subchorionic hematoma, cervical length, and preterm birth. Am J Obstet Gynecol. 2015 Sep; 213(3):403.e1-4. 